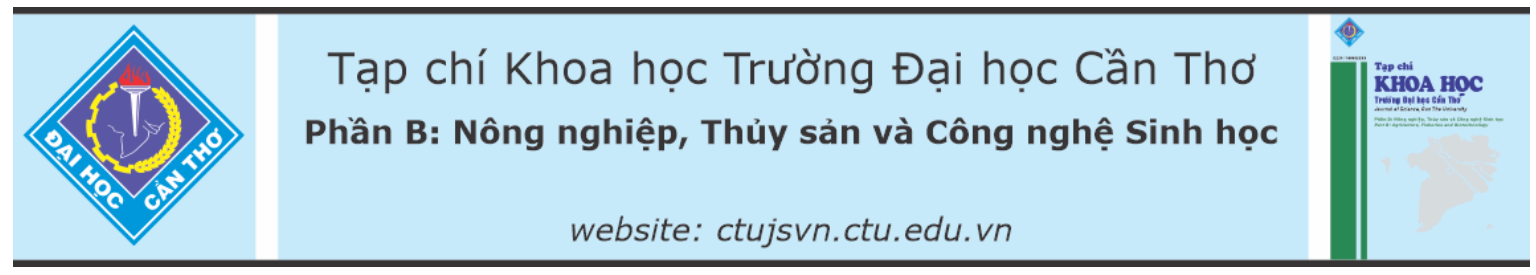

DOI:10.22144/ctu.jvn.2021.177

\title{
ẢNH HƯỞNG CỦA LÁ MÍT VÀ TRÁI MÍT NON PHỤ PHẨM ĐẾN CÁC THÔNG SỐ LÊN MEN DẠ CỎ VÀ SINH KHÍ METHANE in vitro
}

\author{
Lâm Phước Thành ${ }^{1 *}$, Nguyễn Thị Thu Hà ${ }^{1}$, Dương Trần Tuyết Mai ${ }^{1}$, Võ Thị Phượng Tiên ${ }^{1}$, \\ Nguyễn Châu Khánh Vân ${ }^{1}$ và Trần Thị Thuý Hằng ${ }^{2}$ \\ ${ }^{1}$ Bộ môn Chăn nuôi, Khoa Nông nghiệp, Truoòng Đại học Cần Tho \\ ${ }^{2}$ Bộ môn Kỹ thuật Nông nghiệp, Khoa Phát triển Nông thôn, Truờng Đại học Cần Tho \\ *Ngưòi chịu trách nhiệm về bài viết: Lâm Phuoóc Thành (email: phuocthanh@ctu.edu.vn)
}

\section{Thông tin chung:}

Ngày nhận bài: 31/05/2021

Ngày nhận bài sủa: 17/07/2021

Ngày duyệt đăng: 25/12/2021

Title:

Effect of jackfruit leaves and young jackfruits by-product on in vitro ruminal fermentation and methane production

\section{Tù khóa:}

Dê, lá mít, lên men dạ cỏ, methane, tiêu hóa, trái mít non

\section{Keywords:}

Digestibility, goat, jackfruit leaves, methane, ruminal fermentation, young jackfruits

\begin{abstract}
This study aimed to investigate effect of jackfruit leaves (JL) and young jackfruit by-product $(Y J)$ replace for elephant grass $(E G)$ on in vitro digestibility, ruminal fermentation and $\mathrm{CH}_{4}$ production using rumen fluid from 4 male Saanen F2 goats ( $\widehat{0}$ Saanen $\times$ + Bach Thao). The experiment was conducted as a completely randomized design including 5 treatments and 4 replicates. The treatments, beside $40 \%$ dry matter (DM) from concentrated feed for all diets, were diffent replacing of EG by JL and/or YJ, as follows: NT1 - 60\% EG, NT2 $-30 \% E G+30 \% Y J, N T 3-30 \% E G+30 \% J L, N T 4-30 \% E G+15 \% Y J+$ $15 \% \mathrm{JL}$, and NT5 30\% YJ $+30 \% \mathrm{JL}$. Results showed that total VFA concentration was higher in NT3 and NT5 (73.0 vs 74.8\%) compared with the lowest value $(57.7 \%)$ in $N T 1(P<0.05)$. In vitro true digestibility was $78.5 \%$ in NT5 while this was only $68.5 \%$ in NT1 $(P<0.001)$. Feeding NT5 resulted in an increase $(P<0,001)$ of in vitro neutral detergent fiber (45.0\%) compared with NT1 (42.0\%). Concentration of $\mathrm{CH}_{4}$ expressed as $\mathrm{mL} / \mathrm{g}$ DM reduced by $17.3 \%$ in NT5 relative to NT1 $(P<0.01)$. Overall, combined data suggest that use of NT5 diet is effective in reducing in vitro $\mathrm{CH}_{4}$ production while allowing improvements in digestibility and ruminal VFA concentration in goats.
\end{abstract}

\section{TÓM TẮT}

Thi nghiệm được tiến hành nhằm đánh giá ảnh hưởng của việc sủ dụng lá mít (LM) và trái mít non phu phẩm (TM) thay thế cho cỏ voi (CV) đến tỷ lệ tiêu hoá, lên men da cỏ và sinh khi methane $\left(\mathrm{CH}_{4}\right)$ in vitro sủ dung dịch da cỏ tù 4 con dê đục lai Saanen F2 (ô Saanen $\times$ + Bách Thảo). Thi nghiệm được thiết kế theo mô hình hoàn toàn ngẫu nhiên gồm 5 nghiệm thức (NT) và 4 là̀n lặp lại. Ở tất cả các NT, thức ăn hỗn hợp được cố định ở mức 40\% DM. Năm NT thí nghiệm được xây dựng tù̀ sự thay thế $L M$ và/hoạc TM cho CV trong khẩu phần, cu thể nhu sau: $60 \% \mathrm{CV}$ (NT1), 30\% CV + 30\% TM (NT2), 30\% CV +30\% $L M$ (NT3), $30 \% C V+15 \%$ TM + 15\% LM (NT4), và $30 \% T M+30 \% L M$ (NT5). Kết quả cho thấy acid béo bay hoi (VFA) tổng số thấp nhất ở NT1 $(57,7 \%)$ và cao hơn ở NT3 $(73,0 \%)$ và NT5 $(74,8 \%)(P<0,05)$. Tỷ lệ tiêu hóa thạt in vitro cao nhất ở NT5 (78,5\%) và thấp nhất ơ NT1 $(68,5 \%)(P<0,001)$. Tỷ lẹ tiêu hóa xơ trung tính in vitro cao nhất ở NT5 (45,0\%) và thấp nhất ở NT2 $(42,0 \%)(P<0,001)$. Hàm luợng khi $\mathrm{CH}_{4}(\mathrm{~mL} / \mathrm{g} \mathrm{DM})$ giảm $17,3 \%$ ở NT5 so với NT1 $(P<0,01)$. Kết quả cho thẩy NT5 là khẩu phần phù hợp cho việc cải thiện tỷ lẹ tiêu hóa, VFA dạ cỏ và giảm sinh khí $\mathrm{CH}_{4}$ ở dê trong diều kiẹn in vitro. 


\section{GIỚI THIẸU}

Gia súc nhai lại (GSNL) bao gồm dê thịt và dê sữa giữ một vai trò quan trọng trong hệ thống dinh dưỡng và thực phẩm bền vững, vì dê có thể chuyển hóa một cách hiệu quả các nguồn thức ăn có giá trị thấp thành thực phẩm có giá trị cao như thịt và sữa cung cấp cho con người. Những năm gần đây, việc phát triển chăn nuôi dê ngày một tăng, trung bình $+15,5 \%$ /năm do nhu cầu ngày một cao của thị trường và dịch bệnh gia tăng ở các loài gia súc gia cầm khác. Theo Tổng cục Thống kê (2021) tổng đàn dê cả nước là 2.654.573 con, trong đó Đồng bằng sông Cửu Long (ĐBSCL) có 413.361 con. Tuy nhiên, việc phát triển chăn nuôi dê cũng đối mặt với thách thức rất lớn về việc phải đảm bảo nguồn thức ăn xanh cho sự phát triển và sản xuất tốt của dê. Ở lĩnh vực môi trường, việc thải ra một lượng đáng kể khí methane $\left(\mathrm{CH}_{4}\right)$ gây hiệu ứng nhà kính từ hoạt động chăn nuôi GSNL nói chung và chăn nuôi dê nói riêng cũng được xã hội vô cùng quan tâm (O’Mara, 2011).

Distel et al. (2020) cho rằng việc thay thế các nguồn thức ăn truyền thống trong chăn nuôi bằng các nguồn thức ăn thay thế sẽ giúp GSNL lựa chọn thức ăn có lợi cho sức khỏe, dinh dưỡng của chúng, đồng thời giảm các tác động tiêu cực đến môi trường gây ra bởi các hệ thống nông nghiệp. Khi so sánh với các loài GSNL khác thì dê có khả năng cao trong việc tiếp nhận đa dạng các nguồn thức ăn mới khác nhau (Shaheen et al., 2020). Chính vì vậy, việc phát hiện và sử dụng một cách hiệu quả các nguồn thức ăn xanh mới để bổ sung và thay thế cho các thức ăn xanh truyền thống trong chăn nuôi dê là vô cùng quan trọng.

Ở nước ta, nguồn thức ăn xanh từ sản xuất nông nghiệp rất đa dạng và có trữ lượng rất lớn. Trong đó, mít là cây dễ trồng và đang phát triển rất mạnh vào những năm gần đây do mang lại nguồn lợi kinh tế cao. Theo Cục Trồng trọt (2019), năm 2018 cả nước có 26.174 ha mít, sản lượng 307.534 tấn. Trong đó, vùng ĐBSCL có diện tích lớn nhất cả nước với 10.105 ha; chiếm $38,6 \%$ tổng diện tích và $37,1 \%$ sản lượng cả nước. Diện tích trồng mới diễn ra nhanh nhất tại các tỉnh ĐBSCL. Trong năm 2017, nếu diện tích trồng mới chỉ 581 ha thì sang năm 2018 lên tới 2.407 ha, tăng gấp 4,15 lần. Trong năm 2019, diện tích trồng mới khoảng 1.140 ha, tập trung tại tỉnh Tiền Giang, Hậu Giang và Cần Thơ (Cục Trồng trọt, 2019). Chính vì vậy, phụ phẩm từ mít, đặc biệt trái mít non loại thải là rất lớn, có thể sử dụng làm thức ăn cho chăn nuôi dê. Thêm vào đó, lá mít được xem là thức ăn ưa thích của dê (Van et al., 2005), có hàm lượng đạm thô là 15,3\% (Lâm Phước Thành, 2020), cao gấp 1,5 lần so với cỏ. Lá mít có $33,2 \%$ tannin tổng số (Mui et al., 2002), trong đó 17,9\% là tannin cô đặc (Malik et al., 2017). Tannin cô đặc đã được ghi nhận làm giảm sự sản sinh khí $\mathrm{CH}_{4}$ ở GSNL (Malik et al., 2017).

Thực tế trên cho thấy lá và trái mít non có tiềm năng và sản lượng rất lớn để làm thức ăn cho dê. Tuy nhiên, hai nguồn phụ phẩm có tiềm năng lớn này chưa được người dân khai khác hiệu quả để phục vụ cho chăn nuôi dê và có rất ít những đánh giá một cách khoa học về ảnh hưởng của lá và trái mít non lên tiêu hoá, lên men dạ cỏ và sinh khí $\mathrm{CH}_{4}$ ở dê. Chính vì thế, đề tài được thực hiện nhằm đánh giá tác động của việc sử dụng lá và trái mít non đến các thông số lên men, tỷ lệ tiêu hóa và sự sản sinh khí $\mathrm{CH}_{4}$ ở dê trong điều kiện in vitro.

\section{VẠT LIỆU VÀ PHƯƠNG PHÁP}

\subsection{Thời gian và địa điểm}

Thí nghiệm được tiến hành từ tháng 9/202012/2020 tại Trại chăn nuôi thực nghiệm, Khoa Phát triển Nông thôn (Khu Hoà An, Trường Đại học Cần Thơ) và Phòng thí nghiệm Kỹ thuật chăn nuôi GSNL, Bộ môn Chăn nuôi, Khoa Nông nghiệp, Trường Đại học Cần Thơ.

\section{2. Đối tượng}

Bốn con dê đực lai Saanen F2 (o Saanen $\times$ q Bách Thảo), 6 tháng tuổi, khối lượng 19,8 $\pm 1,93 \mathrm{~kg}$ được nuôi tại trại dê ở Khu Hòa An, Trường Đại học Cần Thơ. Dê được nuôi trên chuồng sàn với 4 ngăn, mỗi ngăn nhốt 1 con $(1,2 \mathrm{~m} \times 1,5 \mathrm{~m} \times 1 \mathrm{~m}$; dài $\times$ rộng $\times$ cao). Dê được cho ăn 2 lần/ngày, lần lượt lúc 7 và $17 \mathrm{~h}$ với khẩu phần theo tỷ lệ thức ăn hỗn hợp (TĂHH):cỏ voi là 40:60 $(\% \mathrm{DM})$ trong 1 tuần trước khi tiến hành lấy dịch dạ cỏ. Dê được cung cấp đầy đủ nước uống sạch hằng ngày.

\subsection{Thức ăn trong thí nghiệm}

Cỏ voi được cắt ở trại thực nghiệm chăn nuôi ở Khu Hòa An, Trường Đại học Cần Thơ. Lá mít và trái mít non phụ phẩm sử dụng trong thí nghiệm là từ cây mít Thái (giống Changai) 3-3,5 năm tuổi. Lá mít phụ phẩm được thu từ việc tỉa bỏ những cành đực và cành xấu của cây mít từ 3 hộ dân trồng mít ở thị trấn Ngã Sáu, huyện Châu Thành, tỉnh Hậu Giang. Trái mít non phụ phẩm $(<1 \mathrm{~kg} /$ trái) được thu từ việc tỉa bỏ bớt các trái mít non của hộ dân trồng mít ở xã Hòa An, huyện Phụng Hiệp, tỉnh Hậu Giang. Mẫu cỏ voi, lá mít và trái mít non sau khi thu, được cắt ngắn khoảng $0,5-1 \mathrm{~cm}$, sấy ở nhiệt độ $60^{\circ} \mathrm{C}$ trong 48 giờ, sau đó được nghiền mịn để phân tích thành phần hóa học. 


\subsection{Dịch dạ cỏ và dung dịch nuôi cấy}

Dịch dạ cỏ được lấy từ 4 con dê $(200 \mathrm{~mL} / \mathrm{con})$ vào buổi sáng trước khi cho ăn. Sau khi lấy, dịch dạ cỏ được đựng riêng trong 4 bình thủy cách nhiệt và vận chuyển ngay đến phòng thí nghiệm thuộc Khoa Nông Nghiệp, Trường Đại học Cần Thơ. Sau đó, dịch dạ cỏ được lọc qua các lỗ lưới $1 \mathrm{~mm}$ trước khi tiến hành thí nghiệm.

Dung dịch nuôi cấy (medium) được chuẩn bị theo phương pháp của Menke and Steingass (1988) với vài điều chỉnh về hàm lượng các khoáng chất như sau: giảm $\mathrm{KH}_{2} \mathrm{PO}_{4}$ từ $6,2 \mathrm{~g}$ xuống còn $6,0 \mathrm{~g}$ (dung dịch khoáng đa lượng); tăng $\mathrm{FeCl}_{2} \cdot 6 \mathrm{H}_{2} \mathrm{O}$ từ $0,8 \mathrm{~g}$ lên $8,0 \mathrm{~g}$ (dung dịch khoáng vi lượng). Ngoài ra, dung dịch medium cũng được bổ sung thêm Lcysteine hydrochloride và sodium sulphide. Dung dịch medium được chuẩn bị và sử dụng trong ngày tiến hành thí nghiệm in vitro.

\subsection{Bố trí thí nghiệm và khẩu phần}

Thí nghiệm được chia thành hai thí nghiệm nhỏ: Thí nghiệm 1 áp dụng kỹ thuật sinh khí trong syringe $100 \mathrm{~mL}$ ở điều kiện in vitro để đánh giá về khí tổng số và khí $\mathrm{CH}_{4} \sinh$ ra. Thí nghiệm 2 sử dụng bình ủ thủy tinh $50 \mathrm{~mL}$ để đánh giá về tỷ lệ tiêu hóa và sự lên men ở điều kiện in vitro. Cả 2 thí nghiệm đều được bố trí hoàn toàn ngẫu nhiên gồm 5 nghiệm thức và 4 lần lặp lại (Bảng 1$)$.

Bảng 1. Tỷ lệ thực liệu và thành phần hóa học của khẩu phần

\begin{tabular}{lrrrrr}
\hline \multirow{2}{*}{ Thực liệu } & \multicolumn{5}{c}{ Nghiệm thức $^{\mathbf{1}}$} \\
\cline { 2 - 6 } & NT1 & NT2 & NT3 & NT4 & NT5 \\
\hline Tỷ lệ thực liệu, \%DM & & & & & \\
\hline Thức ăn hỗn hợp & & & & \\
Cỏ voi & 60,0 & 40,0 & 40,0 & 40,0 & 40,0 \\
Trái mít non & - & 30,0 & 30,0 & 30,0 & - \\
Lá mít & - & - & 30,0 & 15,0 & 30,0 \\
Tổng cộng & 100 & 100 & 100 & 100 & 100 \\
\hline Thành phần hóa học của khẩu phần, \%DM & & & & & \\
\hline DM & 45,4 & 45,8 & 51,0 & 48,4 & 51,4 \\
OM & 90,7 & 91,2 & 88,8 & 90,0 & 89,2 \\
CP & 11,5 & 12,5 & 13,6 & 13,0 & 14,5 \\
NDF & 54,3 & 46,3 & 47,1 & 46,7 & 39,1 \\
\hline
\end{tabular}

DM: vật chất khô, OM: vật chất hũu co, CP: đạm thô, NDF: xo trung tính.

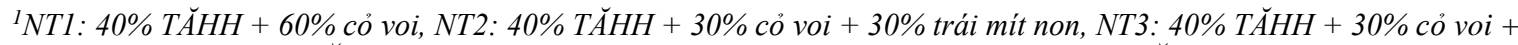

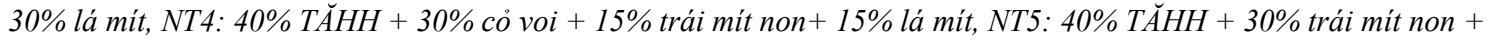
$30 \%$ lá mít

${ }^{2}$ Thức ăn hôn hơp (100\% DM) gồm có: 10,1\% bắp vàng, 10,1 cám gạo tẻ, 8,5\% bánh dầu đậu nành, 9,6\% bánh dầu dùa $0,2 \%$ bột đá vôi $\left(\mathrm{CaCO}_{3}\right), 0,3 \% \mathrm{DCP}, 1,0 \%$ premix vi khoáng và vitamin và $0,3 \%$ muối ăn ( $\mathrm{NaCl}$ ).

\subsection{Tiến hành thí nghiệm in vitro}

Mẫu thức ăn được cân $0,625 \mathrm{~g}$ tương ứng với các nghiệm thức, cho vào syringe thủy tinh có dung tích $100 \mathrm{~mL}$, sau đó thêm $50 \mathrm{~mL}$ dung dịch ủ gồm medium và dịch dạ cỏ (tỷ lệ 4:1). Các syringe được ủ trong water bath lắc tự động (Model: WNB 45, Memmert, Đức) ở 120 vòng/phút và $39^{\circ} \mathrm{C}$ trong 48 $\mathrm{h}$. Lượng khí sinh ra được ghi nhận ở các thời điểm $2,4,6,8,10,12,18,24,36$ và 48 h. Khí sinh ra được thu và trữ trong túi trữ khí chuyên dụng (22952, Restek, US). Hàm lượng các loại khí sinh ra được xác định ở thời điểm $48 \mathrm{~h}$.

Việc xác định tỷ lệ tiêu hoá và các thông số lên men dạ cỏ được thực hiện trên các bình ủ có dung tích $50 \mathrm{~mL}$. Các bình thí nghiệm được ủ trong tủ ủ lắc tự động (ISF-7200R, Jeiotech, Hàn Quốc). Ở thời điểm $24 \mathrm{~h}$ sau khi ủ, các bình ủ được lấy ra để xác định $\mathrm{pH}, \mathrm{NH}_{3}-\mathrm{N}$ và tổng số acid béo bay hơi (volatile fatty acids, VFA). Mẫu dịch dạ cỏ được xác định giá trị $\mathrm{pH}$ bằng máy đo $\mathrm{pH}$ điện tử (Model: HI5522, Hanna Instruments, Mỹ). Mẫu dịch dạ cỏ sau đó được lọc qua 2 lớp vải cotton và phần dịch được acid hóa với dung dịch $\mathrm{H}_{2} \mathrm{SO}_{4} 1 \mathrm{M}$ theo tỷ lệ $10: 1$, trữ đông ở $-20^{\circ} \mathrm{C}$ đến khi phân tích hàm lượng $\mathrm{NH}_{3}-\mathrm{N}$ và $\mathrm{VFA}$. Tỷ lệ tiêu hóa thật (IVTD) và xơ trung tính (IVNDFD) in vitro được xác định tại thời điểm $48 \mathrm{~h}$ theo phương pháp của Van Soest and Robertson (1985).

\subsection{Phương pháp phân tích và tính toán}

Mẫu thức ăn được phân tích vật chất khô (DM), vật chất hữu cơ $(\mathrm{OM})$ và đạm thô $(\mathrm{CP})$ theo phương pháp của AOAC (1990). Xơ trung tính (NDF) được 
phân tích theo phương pháp của Van Soest et al. (1991). Thành phần hóa học được tính toán và trình bày dựa trên $\mathrm{DM}$. Hàm lượng $\mathrm{NH}_{3}-\mathrm{N}$ trong dịch dạ cỏ được phân tích theo phương pháp Kjeldahl (AOAC, 1990), trong khi đó nồng độ VFA được xác định bằng phương pháp chưng cất (Barnett $\&$ Reid, 1957). Nồng độ các khí sinh ra được xác định bằng máy phân tích thành phần khí tự động (Model: GeoTech GA5000, Queensway, UK).

IVTD $(\%)=100 \times(\mathrm{DM}$ của thức ăn được sử dụng để ủ - lượng NDF còn lại sau ủ) / DM của thức ăn được sử dụng để ủ.

IVNDFD $(\%)=100 \times(\mathrm{NDF}$ của thức ăn được sử dụng để ủ - lượng NDF còn lại sau ủ) / NDF của thức ăn được sử dụng để ủ.

\subsection{Xử lý số liệu}

Số liệu thô được xử lý sơ bộ trên phần mềm Microsoft Excel 2019, sau đó được phân tích phương sai theo mô hình tuyến tính tổng quát trên phần mềm Minitab 16.2. Mô hình thống kê được sử dụng là $Y_{i j}=\mu+T_{i}+\varepsilon_{i j}$. Trong đó, $Y_{i j}=$ biến phụ thuộc, $\mu=$ trung bình của chỉ tiêu nghiên cứu, $T_{i}=$ ảnh hưởng cố định của nghiệm thức; $\varepsilon_{i j}=$ sai số ngẫu nhiên. Sự khác biệt thống kê được trình bày khi $P<0,05$ và xu hướng thí nghiệm được trình bày khi $0,05 \leq P<0,10$. Sự khác biệt có ý nghĩa thống kê được kiểm định bằng phương pháp so sánh Tukey sau khi phép thử $\mathrm{F}$ có ý nghĩa.

\section{KẾT QUẢ VÀ THẢO LUẬN}

\subsection{Thành phần hóa học của thực liệu thí nghiệm}

Hàm lượng $\mathrm{DM}$ của cỏ voi trong thí nghiệm là 15,2\% (Bảng 2), tương đương với kết quả của Viện Chăn nuôi Quốc gia (1995) là 15,8\%. Lá mít được sử dụng trong thí nghiệm có $\mathrm{DM}$ là $34,1 \%$, thấp hơn số liệu công bố của Pathoummalangsy et al. (2008) là $36,5 \%$. Lá mít trong thí nghiệm có hàm lượng $\mathrm{CP}$ là $14,1 \%$, cao hơn 2 lần so với hàm lượng $\mathrm{CP}$ của cỏ voi. Đạm thô của lá mít trong thí nghiệm này cao hơn nghiên cứu của Kouch et al. (2003) là $12,8 \%$ và thấp hơn nghiên cứu của Devendra (1992) là 15,1\%. Đạm thô của cỏ voi trong thí nghiệm này tương đương với nghiên cứu của Kha et al. (2020) là $7,27 \%$. Khoáng tổng số của lá mít $(15,2 \%)$ thì cao hơn so với cỏ voi và trái mít non trong thí nghiệm. Lá mít và trái mít non có NDF tương đương nhau $(42,8$ và $45,3 \%)$, trong khi thành phần này trong cỏ voi là lên đến $69,3 \%$.

\section{Bảng 2. Thành phần hóa học của thực liệu}

\begin{tabular}{lrrrrr}
\hline \multirow{2}{*}{ Thực liệu } & \multicolumn{4}{c}{ Thành phần hóa học (\%DM) } \\
\cline { 2 - 6 } & DM & OM & Ash & CP & NDF \\
\hline Thức ăn hỗn hợp & 90,6 & 89,8 & 7,70 & 18,0 & 31,8 \\
Cỏ voi & 15,2 & 91,3 & 8,68 & 7,22 & 69,3 \\
Trái mít non & 16,6 & 92,8 & 7,19 & 10,3 & 42,8 \\
Lá mít & 34,1 & 84,9 & 15,2 & 14,1 & 45,3 \\
\hline
\end{tabular}

DM: vật chất khô, OM: vật chất hũu co: Ash: khoáng tổng số, CP: đạm thô, NDF: xo trung tính.

\subsection{Các thông số lên men và tỷ lệ tiêu hóa}

Sự thay đổi tỷ lệ các loại thức ăn trong khẩu phần không ảnh hưởng đến $\mathrm{pH}$ và $\mathrm{NH}_{3}-\mathrm{N}$ ở $24 \mathrm{~h}$ trong thí nghiệm (Bảng 3). Giá trị pH dịch dạ cỏ dao động trong khoảng $6,78-6,90$, nhìn chung giá trị $\mathrm{pH}$ này nằm trong khoảng bình thường cho hoạt động của vi sinh vật dạ cỏ. Kết quả này tương tự với nghiên cứu của Hiltner \& Dehority (1983), thừa nhận rằng $\mathrm{pH}$ tối ưu trong dạ cỏ phải từ 6,6 đến 7,$0 ; \mathrm{khi}$ chỉ số $\mathrm{pH}$ thấp sẽ có vấn đề trong tiêu hóa xơ (Pitt et al., 1996). Hàm lượng $\mathrm{NH}_{3}-\mathrm{N}$ dao động trong khoảng 41,0$44,8 \mathrm{mg} / \mathrm{dL}$. Belasco (1954) cho rằng mức tiêu hóa xơ (cellulose) sẽ cao nhất khi hàm lượng $\mathrm{NH}_{3}-\mathrm{N}$ trong dạ cỏ là $43 \mathrm{mg} / \mathrm{dL}$. Hàm lượng VFA sinh ra sau 24 h có sự khác biệt có ý nghĩa $(\mathrm{P}<0,05)$. VFA sinh ra thấp nhất ở NT1 với $57,7 \mathrm{mM}$ và cao hơn ở NT3 và NT5, điều này cho thấy nguồn xơ từ lá mít là loại dễ lên men.

\section{Bảng 3. Các thông số lên men và tỷ lệ tiêu hóa}

\begin{tabular}{lrrrrrrr}
\hline \multirow{2}{*}{ Chỉ tiêu $^{1}$} & \multicolumn{9}{c}{ Nghiệm thức $^{\mathbf{2}}$} & \multirow{2}{*}{ SEM } & \multirow{2}{*}{ P } \\
\cline { 2 - 6 } pH 24h & NT1 & NT2 & NT3 & NT4 & NT5 & & 0,327 \\
NH 3 -N 24h, mg/dL & 6,80 & 6,83 & 6,84 & 6,90 & 6,78 & 0,04 & 0,489 \\
VFA 24h, mM & 44,5 & 43,4 & 41,0 & 44,1 & 44,8 & 1,62 & 0,022 \\
IVTD 48h, \% & $57,7^{\mathrm{b}}$ & $65,2^{\text {ab }}$ & $73,0^{\mathrm{a}}$ & $68,8^{\mathrm{ab}}$ & $74,8^{\mathrm{a}}$ & 3,43 & $<0,001$ \\
IVNDFD 48h, \% & $68,5^{\mathrm{d}}$ & $71,1^{\mathrm{c}}$ & $74,2^{\mathrm{b}}$ & $73,4^{\mathrm{b}}$ & $78,5^{\mathrm{a}}$ & 0,39 & $<, 001$ \\
\hline
\end{tabular}

${ }^{1}$ VFA: acid béo bay hơ, IVTD: tỷ lệ tiêu hóa thật in vitro, IVNDFD: tỷ lệ tiêu hóa xo trung tính in vitro. ${ }^{2}$ NT1: $40 \%$

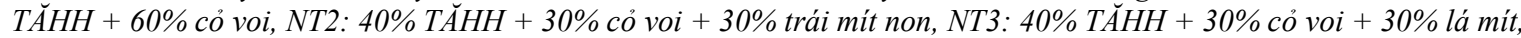
NT4: $40 \%$ TĂHH $+30 \%$ cỏ voi $+15 \%$ trái mít non $+15 \%$ lá mít, NT5: $40 \%$ TĂHH $+30 \%$ trái mít non $+30 \%$ lá mít. ${ }^{a-}$

d: các giá trị cùng hàng có ít nhất 1 ký tụ giống nhau thì khác biệt không ý nghĩa. 
Trong thí nghiệm này, IVTD ở $48 \mathrm{~h}$ dao động trong khoảng $68,5-78,5 \%$, kết quả này phù hợp với nghiên cứu của Lâm Phước Thành (2020) là 65,1$79,3 \%$. IVTD sau $48 \mathrm{~h}$ tăng dần đều từ NT1 đến NT5 $(\mathrm{P}<0,001)$, như vậy có thể thấy khi giảm dần mức cỏ voi và tăng tỷ lệ lá mít, trái mít trong khẩu phần thì cho tỷ lệ tiêu hóa tốt hơn ở điều kiện in vitro. Tỷ lệ tiêu hóa xơ trung tính thấp nhất ở NT2 (37,6\%), cao nhất ở NT3 $(45,3 \%)$ và không có sự khác biệt giữa các nghiệm thức còn lại $(\mathrm{P}<0,001)$. Điều này chứng minh lá mít chứa nguồn xơ dễ tiêu hoá, trong khi thành phần xơ trong trái mít là rất khó tiêu.

\subsection{Lượng khí sinh ra}

Bảng 4 cho thấy tổng lượng khí sinh ra ở NT5 thấp hơn các nghiệm thức còn lại $(\mathrm{P}<0,05)$. Nguyên nhân làm tổng lượng khí sinh ra thấp ở NT5 là do lượng khí $\mathrm{CH}_{4}$ và $\mathrm{CO}_{2}(\mathrm{P}<0,05)$ giảm, tuy $\mathrm{H}_{2} \mathrm{~S}$ có tăng $(\mathrm{P}<0,05)$ nhưng ảnh hưởng không đáng kể đến lượng khí tổng số $\left(\mathrm{H}_{2} \mathrm{~S}\right.$ chỉ chiếm $0,3-0,47 \%$ tổng lượng khí sinh ra). Nhìn chung, nồng độ khí $\mathrm{CH}_{4}$ sinh ra không có sự khác biệt giữa các nghiệm thức $(\mathrm{P}>0,05)$, tuy nhiên NT5 làm giảm lượng khí $\mathrm{CH}_{4}$ sinh ra so với NT1 khi tính theo $\mathrm{mL}$ và $\mathrm{mL} / \mathrm{g} \mathrm{DM}$ lần lượt là 17,2 và $17,4 \%(\mathrm{P}<0,01)$. Lượng khí $\mathrm{CH}_{4}$ sinh ra trong thí nghiệm dao động trong khoảng 30,0-36,3 $\mathrm{mL} / \mathrm{g} \mathrm{DM}$, cao hơn với nghiên cứu của Lâm Phước Thành (2020) khi sử dụng lá mít thay thế cho cỏ sả có lượng khí sinh ra trong 48 h là 19,4$25,6 \mathrm{~mL} / \mathrm{gDM}$.

\section{Bảng 4. Lượng khí sinh ra (48h)}

\begin{tabular}{|c|c|c|c|c|c|c|c|}
\hline \multirow{2}{*}{ Chỉ tiêu ${ }^{1}$} & \multicolumn{5}{|c|}{ Nghiệm thức ${ }^{2}$} & \multirow{2}{*}{ SEM } & \multirow{2}{*}{$\mathbf{P}$} \\
\hline & NT1 & NT2 & NT3 & NT4 & NT5 & & \\
\hline \multicolumn{8}{|l|}{ Khí tổng số } \\
\hline $\mathrm{mL}$ & $145^{\mathrm{a}}$ & $143^{\mathrm{a}}$ & $141^{\mathrm{ab}}$ & $145^{\mathrm{a}}$ & $128^{b}$ & 3,41 & 0,015 \\
\hline $\mathrm{mL} / \mathrm{g} \mathrm{DM}$ & $232^{\mathrm{a}}$ & $229^{\mathrm{a}}$ & $226^{\mathrm{ab}}$ & $232^{\mathrm{a}}$ & $205^{\mathrm{b}}$ & 5,46 & 0,015 \\
\hline $\mathrm{mmol} / \mathrm{g} \mathrm{DM}$ & $10,4^{\mathrm{a}}$ & $10,2^{\mathrm{a}}$ & $10,1^{\mathrm{ab}}$ & $10,4^{\mathrm{a}}$ & $9,1^{\mathrm{b}}$ & 0,24 & 0,015 \\
\hline \multicolumn{8}{|l|}{ Khí $\mathrm{CH}_{4}$} \\
\hline$\%$ & 15,7 & 15,6 & 15,2 & 15,5 & 14,7 & 0,41 & 0,438 \\
\hline $\mathrm{mL}$ & $22,7^{\mathrm{a}}$ & $22,3^{\mathrm{a}}$ & $21,4^{\mathrm{ab}}$ & $22,5^{\mathrm{a}}$ & $18,8^{\mathrm{b}}$ & 0,72 & 0,007 \\
\hline $\mathrm{mL} / \mathrm{g} \mathrm{DM}$ & $36,3^{\mathrm{a}}$ & $35,6^{\mathrm{a}}$ & $34,2^{\mathrm{ab}}$ & $36,0^{\mathrm{a}}$ & $30,0^{\mathrm{b}}$ & 1,15 & 0,007 \\
\hline \multicolumn{8}{|l|}{ Khí $\mathrm{CO}_{2}$} \\
\hline$\%$ & 59,0 & 59,6 & 59,0 & 60,4 & 58,3 & 1,11 & 0,744 \\
\hline $\mathrm{mL}$ & $85,2^{\mathrm{a}}$ & $85,2^{\mathrm{ab}}$ & $83,3^{\mathrm{ab}}$ & $87,5^{\mathrm{a}}$ & $74,6^{\mathrm{b}}$ & 2,55 & 0,021 \\
\hline $\mathrm{mL} / \mathrm{g} \mathrm{DM}$ & $136^{\mathrm{a}}$ & $136^{\mathrm{ab}}$ & $133^{\mathrm{ab}}$ & $140^{\mathrm{a}}$ & $119^{\mathrm{b}}$ & 4,07 & 0,021 \\
\hline \multicolumn{8}{|l|}{ Khí $\mathrm{H}_{2} \mathrm{~S}$} \\
\hline$\%$ & $0,30^{\mathrm{b}}$ & $0,33^{\mathrm{b}}$ & $0,47^{\mathrm{a}}$ & $0,38^{\mathrm{ab}}$ & $0,41^{\mathrm{ab}}$ & 0,03 & 0,012 \\
\hline $\mathrm{mL}$ & $43,7^{\mathrm{b}}$ & $47,1^{\mathrm{ab}}$ & $66,6^{\mathrm{a}}$ & $55,0^{\mathrm{ab}}$ & $52,5^{\mathrm{ab}}$ & 4,72 & 0,034 \\
\hline $\mathrm{mL} / \mathrm{g} \mathrm{DM}$ & $69,9^{\mathrm{b}}$ & $75,4^{\mathrm{ab}}$ & $106,5^{\mathrm{a}}$ & $88,1^{\mathrm{ab}}$ & $83,9^{\mathrm{ab}}$ & 7,55 & 0,034 \\
\hline
\end{tabular}

${ }^{1} D M$ : vật chất khô. ${ }^{2} N T 1: 40 \%$ TĂHH $+60 \%$ cỏ voi, NT2: $40 \%$ TĂHH $+30 \%$ cỏ voi $+30 \%$ trái mít non, NT3: $40 \%$ $T \breve{A H H}+30 \%$ cỏ voi $+30 \%$ lá mít, NT4: $40 \%$ TăHH $+30 \%$ cỏ voi $+15 \%$ trái mít non $+15 \%$ lá mít, NT5: $40 \%$ TĂHH $+30 \%$ trái mít non $+30 \%$ lá mít. ${ }^{a, b}$ : các giá trị cùng hàng có it nhất 1 ký tụ giống nhau thì khác biệt không ý nghĩa.

\subsection{Lượng khí tích lũy}

Hình 1 cho thấy NT5 có lượng khí sinh ra sau 48 $\mathrm{h}$ ủ là thấp nhất. Lượng khí tích lũy ở NT5 sau 24, 36,48 h lần lượt là 111,123 và $128 \mathrm{~mL}$ với $\mathrm{P}<0,05$. Như vậy, khi thay thế hoàn toàn cỏ voi bằng $30 \%$ lá mít và $30 \%$ trái mít non thì lượng khí sinh ra sau 48 $\mathrm{h}$ ủ giảm $11,7 \%$. Trong khi đó, việc sử dụng lá và trái mít non trong khẩu phần không ảnh hưởng đến lượng khí tổng số tích lũy trong giai đoạn trước $24 \mathrm{~h}$ ủ.

Lượng khí sinh ra giảm theo lượng lá mít có trong khẩu phần, tuy nhiên hàm lượng VFA lại tăng. Kết quả này chứng tỏ khí sinh ra giảm khi sử dụng lá mít trong khẩu phần không ảnh hưởng đến sự sản xuất acid béo bay hơi ở dạ cỏ của dê. Điều này cũng chứng tỏ sự lên men ở dạ cỏ diễn ra rất tốt và lượng khí sinh ra bị giảm do lượng $\mathrm{CH}_{4}$ sinh ra giảm. Kết quả này phù hợp với nghiên cứu của Martin et al. (2008) và Malik et al. (2017), sử dụng các hợp chất thứ cấp trong cây thức ăn như tannin đã có tác dụng ngăn chặn sản xuất $\mathrm{CH}_{4}$ trong quá trình lên men ở dạ cỏ. Đối với thức ăn chứa tannin, việc ức chế quá trình sinh $\mathrm{CH}_{4}$ chủ yếu là do tannin cô đặc. Thức ăn chứa tannin sẽ ảnh hưởng trực tiếp đến hình thành $\mathrm{CH}_{4}$ hoặc ảnh hưởng gián tiếp bằng cách giảm tạo hydro do tỷ lệ tiêu hóa thức ăn ở dạ cỏ thấp hơn (Tavendale et al., 2005). Kết quả thí nghiệm này cho 
thấy tannin từ lá và trái mít non đã ảnh hưởng trực tiếp đến hình thành $\mathrm{CH}_{4}$, khi mà tỷ lệ tiêu hoá thật in vitro ở nghiệm thức chứa lá và trái mít non cao hơn nghiệm thức đối chứng.

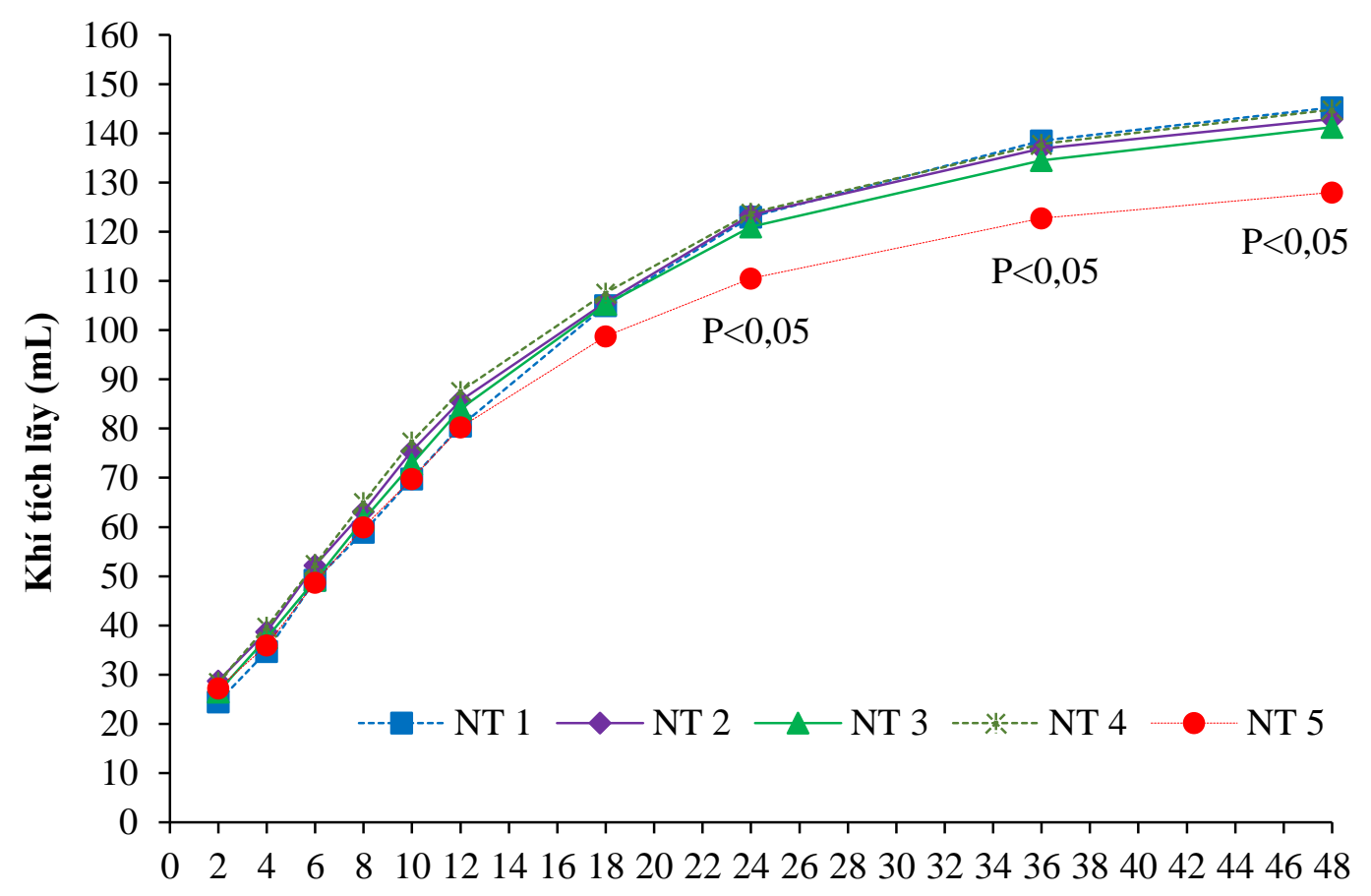

Thời gian ủ (h)

Hình 1. Lượng khí tích lũy theo thời gian ủ

\section{KẾT LUẬN VÀ ĐỀ XUẤT}

\subsection{Kết luận}

Nghiệm thức NT3 (40\% TĂHH $+30 \%$ cỏ voi + $30 \%$ lá mít) và NT5 $(40 \%$ TĂHH $+30 \%$ trái mít non $+30 \%$ lá mít) có hàm lượng VFA sinh ra cao hơn lần lượt là $26,5 \%$ và $29,7 \%$ so với $\mathrm{NT} 1$. Nghiệm thức NT5 có tỷ lệ tiêu hóa thật in vitro cao nhất và đồng thời giảm sinh khí $\mathrm{CH}_{4}$ ở in vitro đến $17,3 \%$ so với NT1. Kết quả thí nghiệm cho thấy thay thế cỏ voi bằng $30 \%$ trái mít non $+30 \%$ lá mít là giải pháp hiệu quả để cải thiện tỷ lệ tiêu hóa, VFA dạ cỏ và giảm sinh khí $\mathrm{CH}_{4}$ ở dê trong điều kiện in vitro. Do đó, việc sử dụng $30 \%$ trái mít non $+30 \%$ lá mít thay thế cho cỏ voi trong khẩu phần của dê có thể giúp sử dụng có hiệu quả các nguồn thức ăn sẵn có, tăng năng suất gia súc và thân thiện với môi trường.

\section{2. Đề xuất}

Việc thực hiện thêm các nghiên cứu trên gia súc sử dụng lá và trái mít non trong khẩu phần với thời gian thí nghiệm dài hơn và số lượng gia súc nhiều hơn để đánh giá về ảnh hưởng của lá và trái mít non phụ phẩm lên năng suất và chất lượng thịt và sữa là cần thiết.

\section{LỜI CẢM TẠ}

Đề tài này được tài trợ một phần bởi Dự án Nâng cấp Trường Đại học Cần Thơ VN14-P6 bằng nguồn vốn vay $\mathrm{ODA}$ từ chính phủ Nhật Bản, mã đề tài $\mathrm{A} 9$.

\section{TÀI LIỆU THAM KHẢO}

AOAC. (1990). Official Methods of Analysis (15 ${ }^{\text {th }}$ ed.). Association of Official Analytical Chemists.

Barnett, A. J. G., \& Reid, R. L. (1957). Studies on the production of volatile fatty acids from grass by rumen liquor in an artificial rumen. 2 . The volatile fatty acid production from dried grass. Journal of Agricultural Science, 49(2), 171-179. https://doi.org/10.1017/S0021859600036157

Belasco, I. J. (1954). Comparison of urea and protein meals as nitrogen sources for rumen microorganisms: urea utilization and cellulose digestion. Journal of Animal Science, 13(4), 739747. https://doi.org/10.2527/jas1954.134739x

Cục Trồng Trọt. (12/7/2019). Cục Trồng Trọt lên tiếng cảnh báo việc dân trồng ồ ạt cây mít Thái. https://agrinews.vn/cuc-trong-trot-len-tiengcanh-bao-viec-dan-trong-o-at-cay-mit-thai-2/.

Devendra, C. (1992). Nutritional potential of fodder trees and shrubs as protein sources in ruminant 
nutrition. In A. Speedy \& P.L. Pugliese (Eds.), Legume trees and other fodder trees as protein sources for livestock (pp. 95-113). FAO-Animal Production and Health Paper.

Distel, R. A., Arroquy, J. I., Lagrange, S., \& Villalba, J. J. (2020). Designing diverse agricultural pastures for improving ruminant production systems. Frontiers in Sustainable Food Systems, 4(215). https://doi.org/10.3389/fsufs.2020.596869.

Hiltner, P., \& Dehority, B. A. (1983). Effects of soluble carbohydrates on diction of cellulose by pure cultures of rumen bacteria. Applied Microbiology and Biotechnology, 46(3), 642648. https://doi.org/10.1128/aem.46.3.642648.1983

Kha, P. T. T., Tham, H. T, Hang, T. T. T, \& Thanh, L. P. (2020). Effects of oils and condensed tannins on ruminal fermentation and methane emission in dairy cows, The $3^{\text {rd }}$ International Conference on Sustainable Agriculture and Environment (pp. 182-191). NXB Đại học Quốc Gia TP Hồ Chí Minh.

Pathoummalangsy, K., \& Preston, T. R. (2008). Effects of supplementation with rumen fermentable carbohydrate and sources of by pass protein on feed intake, digestibility and $\mathrm{N}$ retentioning rowing goats fed a basal diet of foliage of Tithonia diversifolia. Livestock Research for Rural Development, 20(Suppl.).

Kouch, T., Preston, T. R., \& Ly, J. (2003). Studies on utilization of trees and shrubs as the sole feedstuff by growing goats; foliage preferences and nutrient utilization. Livestock Research for Rural Development, 15(7).

Lâm Phước Thành. (2020). Ảnh hưởng của lá mít lên tỷ lệ tiêu hóa, lên men dạ cỏ và sinh khí methane ở dê. Tạp chí Khoa học Kỹ thuật Chăn nuôi, 260, 62-66.

Malik, P. K., Kolte, A. P., Baruah, L., Saravanan, M., Bakshi, B., \& Bhatta, R. (2017). Enteric methane mitigation in sheep through leaves of selected tanniniferous tropical tree species. Livestock Science, 200, 29-34. https://doi.org/10.1016/j.livsci.2017.04.001

Martin, C., Rouel, J., Jouany, J. P., Doreau, M., \& Chilliard, Y. (2008). Methane output and diet digestibility in response to feeding dairy cows crude linseed, extruded linseed, or linseed oil. Journal of Animal Science, 86(10), 2642-2650. https://doi.org/10.2527/jas.2007-0774

Menke, K. H., \& Steingass, H. (1998). Estimation of the energetic feed value obtained from chemical analysis and gas production using rumen fluid. Animal Research and Development, 28, 7-55.

Mui, N. T., Ledin, I., Uden, P., \& Binh, D. V. (2002). The foliage of Flemingia (Flemingia macrophylla) or Jackfruit (Artocarpus heterophyllus) as a substitute for a rice bran-soya bean concentrate in the diet of lactating goats. Asian-Australasian Journal of Animal Sciences, 15(1), 1-10. https://doi.org/10.5713/ajas.2002.45

O'Mara, F.P. (2011). The significance of livestock as a contributor to global greenhouse gas emissions today and in the near future. Animal Feed Science and Technology, 166-167, 7-15. https://doi.org/10.1016/j.anifeedsci.2011.04.074

Pitt, R. E., Van Kessel, J. S., Fox, D. G., Pell, A. N., Barry, M. C., \& Van Soest, P. J. (1996). Prediction of ruminal volatile fatty acids and $\mathrm{pH}$ within the net carbohydrate and protein system. Journal of Animal Science, 74(1), 226-244. https://doi.org/10.2527/1996.741226x

Shaheen, H., Qureshi, R., Qaseem, M. F., \& Bruschi, P. (2020). The fodder grass resources for ruminants: A indigenous treasure of local communities of Thal desert Punjab, Pakistan. PloS one, 15(3), e0224061. https://doi.org/10.1371/journal.pone.0224061

Tavendale, M. H., Meagher, L. P., Pacheco, D., Walker, N., Attwood, G. T., \& Sivakumaran, S. (2005). Methane production from in vitro rumen incubations with Lotus pedunculatus and Medicago sativa, and effects of extractable condensed tannin fractions on methanogenesis. Animal Feed Science and Technology, 123-124, 403-419. https://doi.org/10.1016/j.anifeedsci.2005.04.037

Tổng cục thống kê (4/2021). Thống kê chăn nuôi Việt Nam 01/01/2021 về số lượng đầu con và sản phẩm gia súc, gia cầm.

https://channuoivietnam.com/thong-ke-channuoi/tk-chan-nuoi/

Van Soest, P. J., Robertson, J. B., \& Lewis, B. A. (1991). Symposium: Carbohydrate methodology, metabolism and nutritional implications in dairy cattle: methods for dietary fibre, and nonstarch polysaccharides in relation to animal nutrition. Journal of Dairy Science, 74(10), 3585-3597.

Van Soest, P., \& Robertson, J. B. (1985). A Laboratory Manual for Animal Science. Cornell University. https://doi.org/10.3168/jds.S00220302(91)78551-2

Van, D. T. T., Mui, N. T., \& Ledin, I. (2005). Tropical foliages: effect of presentation method and species on intake by goats. Animal Feed Science and Technology, 118(1-2), 1-17. https://doi.org/10.1016/j.anifeedsci.2004.10.016

Viện Chăn nuôi Quốc gia. (1995). Thành phàn và giá trị dinh duõng thức ăn gia súc, gia cầm Việt Nam. NXB Nông nghiệp. 